\title{
Hydroalcoholic crude extract of Casearia sylvestris Sw. reduces chronic post-ischemic pain by activation of pro-resolving pathways
}

\author{
Anna P. Piovezan ${ }^{\mathrm{a}, \mathrm{b}, \mathrm{c}, *}$, Ana P. Batisti ${ }^{\mathrm{a}, \mathrm{b}}$, Maria L.A.C.S. Benevides ${ }^{\mathrm{b}, \mathrm{d}}$, Bruna L. Turnes ${ }^{\mathrm{e}}$, Daniel \\ F. Martins ${ }^{\mathrm{a}, \mathrm{b}}$, Luiz Kanis ${ }^{\mathrm{a}}$, Elisa C.W. Duarte ${ }^{\mathrm{f}}$, Alberto J. Cavalheiro ${ }^{\mathrm{g}}$, Paula C.P. Bueno ${ }^{\mathrm{g}}$, Michael \\ P. Seed ${ }^{\mathrm{h}}$, Lucy V. Norling ${ }^{\mathrm{c}}$, Dianne Cooper ${ }^{\mathrm{c}}$, Sarah Headland ${ }^{\mathrm{c}}$, Patrícia R.P.S. Souza ${ }^{\mathrm{c}}$, \\ Mauro Perretti ${ }^{\mathrm{c}}$
}

a Post-Graduate Programm in Health Science - Southern Univeristy of Santa Catarina (UNISUL), Brazil

b Laboratory of Experimental Neuroscience (LANEX)- UNISUL, Brazil

c William Harvey Research Institute - Queen Mary University of London/London, UK

${ }^{\mathrm{d}}$ Undergraduation in Medicine - UNISUL, Brazil

e Laboratory of Neurobiology of Pain and Inflammation - UFSC, Brazil

${ }^{\mathrm{f}}$ Department of Morphological Science - UFSC, Brazil

${ }^{g}$ Department of Organic Chemistry/Institute of Chemistry - UNESP, Brazil

${ }^{\mathrm{h}}$ Clinical Research Group, School of Health Sport \& Bioscience, University of East London, UK

\section{A R T I C L E I N F O}

\section{Keywords:}

Casearia sylvestris

Salicaceae

Chronic post-ischemia pain

Inflammation

ALX/FPR2

\begin{abstract}
A B S T R A C T
Ethnopharmacological relevance: Casearia sylvestris Sw. is widely used in popular medicine to treat conditions associated with pain.

Aim of the study: The present study investigated the influence of hydroalcoholic crude extract of Casearia sylvestris (HCE-CS) and contribution of pro-resolving mediators on mechanical hyperalgesia in a mouse model of chronic post-ischemia pain (CPIP).

Methods and results: Male Swiss mice were subjected to ischemia of the right hind paw $(3 \mathrm{~h})$, then reperfusion was allowed. At $10 \mathrm{~min}, 24 \mathrm{~h}$ or $48 \mathrm{~h}$ post-ischemia/reperfusion (I/R), different groups of animals were treated with HCE-CS (30 mg/Kg, orally [p.o]), selected agonists at the pro-resolving receptor ALX/FPR2 (natural molecules like resolvin D1 and lipoxin A4 or the synthetic compound BML-111; 0.1-1 $\mu \mathrm{g} / \mathrm{animal}$ ) or vehicle (saline, $10 \mathrm{~mL} / \mathrm{Kg}$, s.c.), in the absence or presence of the antagonist WRW4 (10 $\mu$ g, s.c.). Mechanical hyperalgesia (paw withdrawal to von Frey filament) was asseseed together with histological and immunostainning analyses. In these settings, pro-resolving mediators reduced mechanical hyperalgesia and HCE-CS or BML111 displayed anti-hyperalgesic effects which was markedly attenuated in animals treated with WRW4. ALX/ FPR2 expression was raised in skeletal muscle or neutrophils after treatment with HCE-CS or BML-111.

Conclusion: These results reveal significant antihyperalgesic effect of HCE-CS on CPIP, mediated at least in part, by the pathway of resolution of inflammation centred on the axis modulated by ALX/FPR2.
\end{abstract}

\section{Introduction}

We have previously reported that the hydroalcoholic crude extract from Casearia sylvestris Sw. (HCE-CS) exert several actions on specific responses of pain and inflammation. Antinociceptive actions were evident in animal models of nociceptive, inflammatory and immune mediated pain (De Mattos et al., 2017); furthermore, the HCE-CS was also endowed with anti-inflammatory properties in the model of carrageenan-paw edema in mice, as well as in pleurisy model in rats reducing neutrophil recruitment and nitrite/nitrate production in pleural exsudate (Albano et al., 2013).

The Casearia sylvestris specie was recently related to the family of Salicaceae (Ferreira et al., 2011) and contains phytochemicals from different classes of medicinal interest such as sesqui- (Bou et al., 2013)

\footnotetext{
* Correspondence to: University of Southern Santa Catarina, Campus Grande Florianópolis, Avenida Pedra Branca, 25, Palhoça, SC, CEP 88137-270, Brazil.

E-mail addresses: anna.piovezan@unisul.br (A.P. Piovezan), anapaulabatisti@hotmail.com (A.P. Batisti), marialb994@hotmail.com (M.L.A.C.S. Benevides), brunalenferss@hotmail.com (B.L. Turnes), danielmartinsfisio@hotmail.com (D.F. Martins), luizalbertokanis@gmail.com (L. Kanis), ijawinkel@yahoo.com.br (E.C.W. Duarte), albjcava@gmail.com (A.J. Cavalheiro), paulabueno@yahoo.com (P.C.P. Bueno), m.p.seed@uel.ac.uk (M.P. Seed), l.v.norling@qmul.ac.uk (L.V. Norling), d.cooper@qmul.ac.uk (D. Cooper), sarah.Headland@ucsf.edu (S. Headland), p.soaresdesouza@qmul.ac.uk (P.R.P.S. Souza), m.perretti@qmul.ac.uk (M. Perretti).
} 
and diterpenes (Meesakul et al., 2016). Among this last class, Dos Santos and colleagues (Dos Santos et al., 2010) recently reported the isolation of five new compounds, termed casearins and casearvestrins. Together with other coumpounds, casearins can be able to inhibit the activity of phospholipase $\mathrm{A}_{2}\left(\mathrm{PLA}_{2}\right)$ (Borges et al., 2000, 2001), which seems to be a property in agreement with the ethnopharmacological use of the plant in popular medicine for the treatment of wounds and ulcers or against snake bites (Ferreira et al., 2011). Collectively, these results raise the possibility that the plant could exert antinociceptive and anti-inflammatory effects based on mechanisms relied on resolution of inflammation pathways in other unexplored models of pain and inflammation, since $\mathrm{PLA}_{2}$ is also targeted by others pro-resolving mediators.

The resolution of inflammation is a programmed response from the organism to enable the end of the inflammatory process and ensure that the affected organ goes back to its pre-inflammatory settings and function (Perretti, 2015). Specific pro-resolving mediators and pathways are operative to enact resolution including those centred on annexin A1 (AnxA1) and lipoxin A4 (LXA4) (Cash et al., 2014). Accumulating evidence from diverse animal models indicate modulatory properties for pro-resolving mediators on nociception (Pei et al., 2011; Pierretti et al., 2001) and hyperalgesia (Abdelmoaty et al., 2013; Hu et al., 2012; Huang et al., 2011), through mechanisms that involve modulation of the expression of transcriptional factors and cytokines (Liu et al., 2016; Sun et al., 2012; Wang et al., 2014). Similarly, pivotal roles for the endogenous local signals that govern resolution to impact on pain processes have already defined (for review: Serhan, 2008). Against this background, we speculated a possible synergism of action for both HCE-CS and pro-resolving mediators on pain associated with inflammatory processes, the main example here being chronic postischemic pain (CPIP) typical of the Complex Regional Pain SyndromeType I (CRPS-I).

CRPS-I model is able to faithfully reproduce many of the symptoms related to this syndrome in humans such as hyperalgesia, edema, vasomotor dysfunction and trophic changes (Laferrière et al., 2008). Using this model, after induction of ischemia and reperfusion (I/R) in the hindpaw of animals, is possible to evaluate an initial phase of paw edema and inflammatory pain (up to 3 days after reperfusion) followed by a form of neuropatic pain (from 7 to 21 days after reperfusion) (Martins et al., 2013; Millecamps et al., 2010). Studies have elucidated few aspects of the histology of the skin and microvasculature of the paw tissues after I/R (Coderre and Bennett, 2010; Millecamps, 2010), yet joints and skeletal muscle have not been investigated, both in the absence or presence of specific pharmacological treatments. Herein, we aimed to investigate the effect of HCE-CS or pro-resolving mediators on mechanical hyperalgesia observed in CRPS-I through behavioral and histological analysis, as well as establish a possible influence of resolution of inflammation pathways to the effects of the plant extract.

\section{Material and methods}

\subsection{Preparation and characterization of the hydroalcoholic crude extract of Casearia sylvestris (HCE-CS)}

Extract was obtained from leaves of the plant collected at the botanical Horto at the campus of University Southern Santa Catarina (UNISUL), in the municipality of Tubarão, Santa Catarina, Brazil (latitude $28^{\circ} 28^{\prime} 00^{\prime \prime}$ south and longitude $49^{\circ} 00^{\prime} 25^{\prime \prime}$ west) and prepared as previously described (Albano et al., 2013) and the plant was identified by direct comparison with a voucher specimen (SRS-174) deposited at the herbarium Laelia Purpurata (SRS) at this university. Concentrated HCE of Casearia sylvestris was then stored in a desiccator until the moment of use.

The HCE-CS was analysed by ultra-high performance liquid chromatography coupled to diode array detection (UHPLC-DAD) using water (A) and acetonitrile (B) as eluents and a solid core C18 chromatographic column (Kinetex C18, 150×2.1 mm, $2.6 \mu \mathrm{m}, 100 \AA$ ) according to the method previously developed (Bueno et al., 2015). A volume of $2 \mu \mathrm{L}$ of each sample and the points of the analytical curve were injected in triplicate under the following elution gradient: 10$25 \%$ of B for $15 \mathrm{~min}$ and then $25-90 \%$ of B for $20 \mathrm{~min}$, remaining in this condition for $5 \mathrm{~min}$. A method for reconditioning was incorporated so that it returned to the initial condition in $2 \mathrm{~min}$ and remained in that condition for another $3 \mathrm{~min}$, for a total time of $45 \mathrm{~min}$. The flow rate was $0.4 \mathrm{~mL} / \mathrm{min}$, with column temperature at $35^{\circ} \mathrm{C}$, detection range 200-800 $\mathrm{nm}$ and plotting the chromatograms at $235 \mathrm{~nm}$.

Identification of the main compounds was achieved by ultra-high performance liquid chromatography coupled to mass spectrometry in positive mode (UHPLC-ESI-MS, Amazon SL, Bruker Daltonics) with the aid of previously isolated standards and information from literature. The chromatographic conditions were the same as described above. The ion trap operated in enhanced resolution mode with a capillary potential of $140 \mathrm{~V}$. The capillary temperature was set at $300{ }^{\circ} \mathrm{C}$ with a nebulizer pressure of $30 \mathrm{psi}$ and a dry gas flow of $8 \mathrm{~L} \mathrm{~min}^{-1}$.

From an analytical curve based on caseargrewiin $\mathrm{F}$ was possible to determine the concentration of total casearins in the HCE-CS. For each sample, the total of casearins content was calculated by summing the areas of all peaks corresponding to this compounds in the chromatograms and expressing the results as a function of caseargrewin F. It is important to note that, for such substances, the spectra in the ultraviolet region have a characteristic peak at $225-235 \mathrm{~nm}$ (Fig. 1A). The total casearins content was $18.6 \mathrm{mg} / \mathrm{g}$ (or $1.86 \% \mathrm{~m} /$ $\mathrm{m}$ ), with a standard deviation of $0.8 \%$ (Fig. 1B).

\subsection{Animals}

All experiments were conducted using male Swiss or C567BL-6 mice (wild type or knock out for AnxA1), weighting 25-35 g, housed at $22 \pm 2{ }^{\circ} \mathrm{C}$, under a $12 \mathrm{~h}$ light/12 h dark cycle (lights on at 06:00 h) and with free access to food and water. Mice were acclimated to the Laboratory of Experimental Neuroscience (Lanex), at UNISUL/ Brazil-SC for at least $1 \mathrm{~h}$ before the tests that were carried out between 08:00 and 12:00 a.m. Animals were used only once throughout the experiments. All animal care and experimental procedures were carried out in accordance with the National Institutes of Health Animal Care Guidelines (NIH publications No. 80-23) and were approved by the Ethics Committee for Animal Use (CEUA)-UNISUL, under protocol number 13.036.4.03. IV. The number of animals and intensity of noxious stimuli used were the minimum necessary to demonstrate the consistent effects of treatments. Experimenters were blinded to treatment conditions.

\subsection{Hindpaw ischemia and reperfusion}

The animal model of CPIP was generated following exposure to prolonged hind paw $\mathrm{I} / \mathrm{R}$ and was carried out according to the procedure described for rats (Coderre et al., 2004) and adapted for mice (Millecamps et al., 2010). Mice were anesthetized over a $3 \mathrm{~h}$ period with a bolus $(7 \%, 0.6 \mathrm{~mL} / \mathrm{kg}$, i.p.) of chloral hydrate and $20 \%$ of the initial volume at the end of the first and second hour. After induction of anesthesia, an elastic O-ring for braces (Elástico Ligadura 000-1237, Uniden, SP, Brazil) with $1.2 \mathrm{~mm}$ internal diameter was placed around the right hind limb just proximal to the ankle joint. The O-rings were selected to provide a tight-fit that produced ischemia. They were left on the limb for $3 \mathrm{~h}$ as initially described with larger Orings. The O-ring was always positioned at a point on the limb just proximal to the medial malleolus. Sham mice were subjected to the same procedure except that the O-ring was cut so that it only loosely surrounded the ankle and did not occlude blood flow to the right hind paw (Martins et al., 2013). 


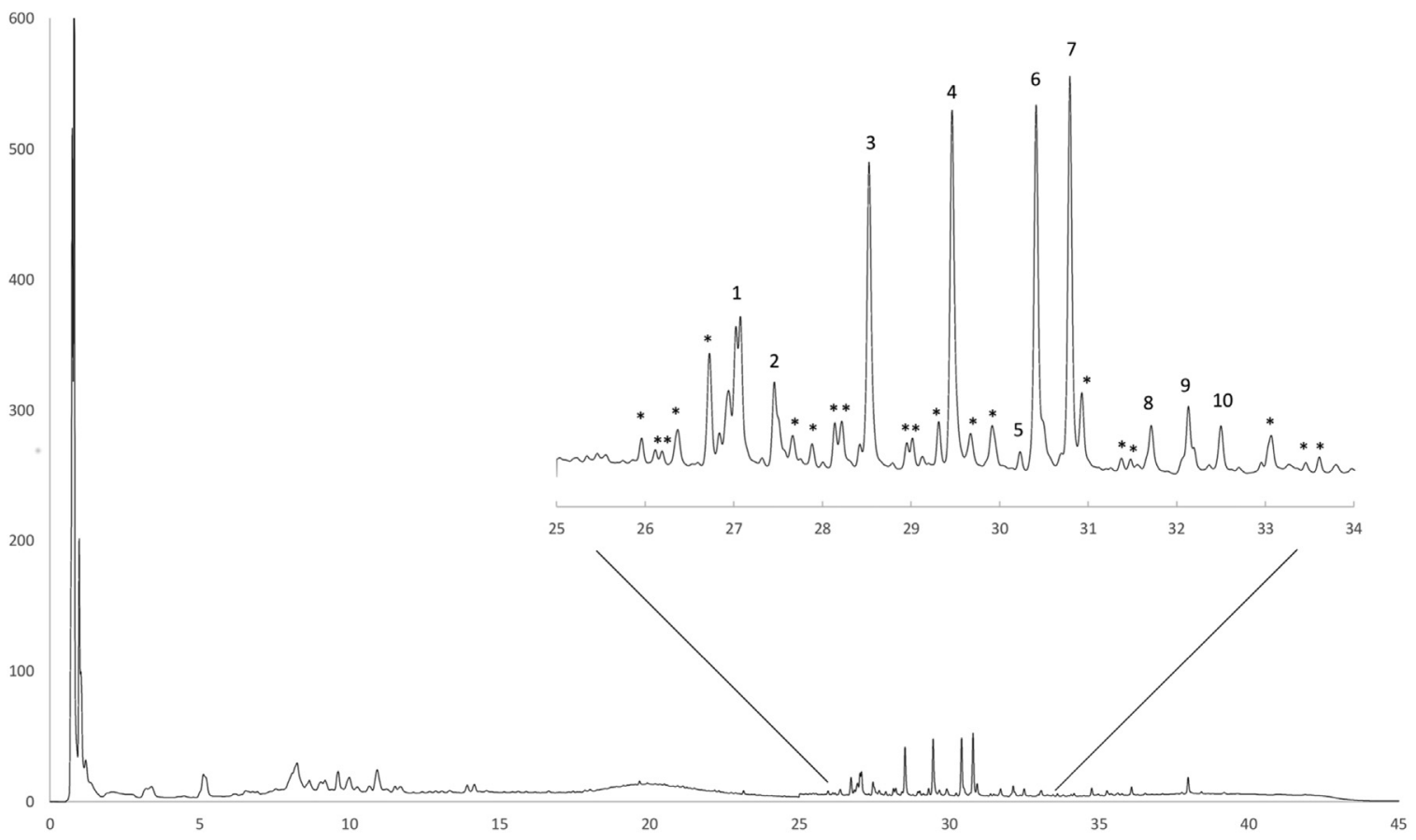

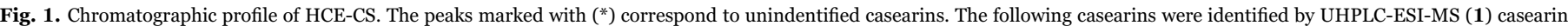

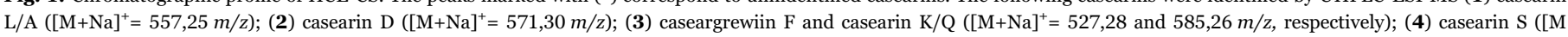

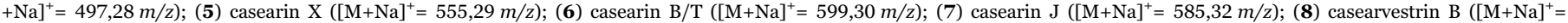
$541,29 \mathrm{~m} / \mathrm{z}) ;(9)$ casearin $\mathrm{O} / \mathrm{N}\left([\mathrm{M}+\mathrm{Na}]^{+}=627,32 \mathrm{~m} / \mathrm{z}\right) ;(\mathbf{1 0})$ casearin $\mathrm{E}\left([\mathrm{M}+\mathrm{Na}]^{+}=613,36 \mathrm{~m} / \mathrm{z}\right)$.

\subsection{Assessment of mechanical hyperalgesia in Swiss mice}

The characteristic mechanical hyperalgesia of CPIP induced by the $\mathrm{I} / \mathrm{R}$ procedure was assessed using von Frey monofilaments (VFH, Stoelting, Chicago, USA), measured as the frequency of response (in percentage) of paw withdrawal from the tested animals, to 10 applications of a von Frey filament with a force of $0.6 \mathrm{~g}$. The test was performed using a platform $(70 \mathrm{~cm} \times 40 \mathrm{~cm})$, which consists of a wire screen mesh of $6 \mathrm{~mm}$ to facilitate the application of the filament on the ventral surface of the hind paw of the animals. Mice were individually placed in an observation chamber made of acrylic $(9 \mathrm{~cm} \times 7 \mathrm{~cm} \times 11 \mathrm{~cm})$, which had no bottom and was covered. The following criteria for applying the mechanical stimuli were considered: a) application was made perpendicularly to the plantar surface with sufficient pressure to provide the curvature of the filament, obtaining the total pressure, b) the animals were assessed when all four paws were accommodated on the screen, c) the withdrawal response was considered positive when the animal completely removed its paw from the surface of the screen. The mechanical hyperalgesia was evaluated before the I/R (basal values) and at different times after treatment.

In a first set of experiments, we evaluated the possible contribution of pro-resolving mediators in synergism with HCE-CS. To this end, $10 \mathrm{~min}, 24$ and $48 \mathrm{~h}$ after induction of I/R the animals were treated with different doses of the mediators resolvin D1 (RvD1, $0.1 \mu \mathrm{g}$, endovenously [e.v.]), an agonist for the GPR32 and ALX/FPR2 receptors or 15-epi-LXA4 (a LXA4 stable analog, $1 \mu \mathrm{g}$, e.v.) and BML-111 (a synthetic analog of the LXA4; doses of $0.1,0.3$ or $1 \mu \mathrm{g} /$ animal, subscutaneously [s.c.]), agonists for the ALX/FPR2 receptor. Mechanical hyperalgesia was assessed up to $72 \mathrm{~h}$ after the $\mathrm{I} / \mathrm{R}$ procedure.

In a second set of experiments, animals were treated after induction of CPIP (same period of time as in first experiments) with vehicle (5\% tween $80,10 \mathrm{~mL} / \mathrm{Kg}$, p.o.), HCE-CS (30 mg/Kg, p.o.), dexamethasone (0.5 mg/Kg, p.o.) or BML-111 (1 $\mu \mathrm{g} / \mathrm{animal}$, s.c.). Mechanical hyperalgesia was assessed $49 \mathrm{~h}$ after the I/R procedure.

Finally, to assess the possible involvement of endogenous ALX/
FPR2 in the antihyperalgesic effect induced by HCE-CS or proresolving mediators in this model, $48 \mathrm{~h}$ after I/R, two groups of animals were treated with vehicle ( $5 \%$ tween $80,10 \mathrm{~mL} / \mathrm{Kg}$, p.o.) or WRW4 (receptor antagonist, $10 \mu \mathrm{g} /$ animal, s.c.). After $15 \mathrm{~min}$, animals then received HCE-CS (30 mg/Kg, p.o.) or BML-111 (1 $\mu \mathrm{g} /$ animal, s.c.) and mechanical hyperalgesia was assessed $49 \mathrm{~h}$ after the I/R procedure.

\subsection{Functional impact of the AnxA1 pathway on CPIP}

The role of endogenous AnxA1 pathway on CPIP was investigated by assessing mechanical hyperalgesia in CRPS-I model using C567BL-6 wild type $\left(\mathrm{AnxA1}^{+/+}\right)$and knock out $\left(\mathrm{AnxA1}^{-/-}\right)$mice, with analyses conducted at the $48 \mathrm{~h}$ time-point.

\subsection{Histological analysis}

Samples obtained from the in vivo experiments were processed according to the type of ex vivo analysis as described below. Since histology for skeletal muscle or joints (cartilage or pannus formation) had never been evaluated during the inflammatory phase of CRPS-I model, the samples of animal paws removed at $49 \mathrm{~h}$ after reperfusion.

Samples were embedded in paraffin, cut into microtome sections $(5 \mu \mathrm{m})$ and mounted on glass slides to assess the tissue changes in animals from different groups after $\mathrm{I} / \mathrm{R}$ procedure. For muscle investigation, samples were processed for staining and analysis using methodolgy previously described (Norling et al., 2016; Headland et al., 2015).

Acquired images were amplified and analysed through the ImagePro Plus ${ }^{\circledR}$ software by counting the number of cells present in a delimited area of $10 \%$ of the total image by using a tag point marker and registered as the number of cells $/ 10 \%$ of the image. For cartilage and pannus assessment, images encompassing the joint areas of the tarsus (tarsus-navicular and navicular-cuneiform-proximal metatarsal) and metatarsal areas (cuboid-metatarsal joint, intermediate region of the metatarsal and phalangeal-metatarsal joint) were evaluated for the 
pannus by the presence along the synovial structures (grade 0: no pannus; grade 1: pannus presence along the synovium, grade 2: marginal pannus and invading the synovium). Finally, cartilage erosion was assessed from images encompassing the tarsus-navicular area of the phalangeal-metatarsal joint analysed by using the Image ${ }^{\circ}$ software, in which images were divided within the channels of different colours (red, green and blue) and images were selected from the channel that best represented the positive and negative stainning in the samples. A colouring threshold was applied to the image of that channel, tracing the total cartilage area from which the software removed the erosion area (without staining), resulting in the percentage of the remaining cartilage area without erosion.

\subsection{Characterization of cell types in the inflammatory infiltrate}

Given that the one of the most accentuated phenomen observed during inflammatory phase is the edema (with plasma and cell extravasation from the vessel), histological analyses in the hind paw of the animals subjected to I/R-induced injury also examined the type of inflammatory cell present in the infiltrate, $49 \mathrm{~h}$ after paw reperfusion according to techniques previously registered (Leinster et al., 2012). This evaluation was performed using the immunofluorescence technique with samples of hind paws of animals belonging to different treatment groups, which were embedded in paraffin, cut into microtome sections $(5 \mu \mathrm{m})$ and mounted on glass slides with subsequent rehydration. Antigen retrieval was performed in citrate buffer ( $\mathrm{pH}$ 6.0) at $94{ }^{\circ} \mathrm{C}$ for $30 \mathrm{~min}$, followed by incubation in hydrogen peroxide solution $(0.3 \%)$ to block endogenous peroxidases. To identify macrophages or lymphocytes in cell infiltrates, samples were incubated overnight with primary antibodies against CD68 (Zymed, 1:100) or CD3 (Santa Cruz, 1:200), respectively. An antibody diluent was added to the negative control group in this stage (bovine serum albumin, 1\% BSA). Following addition of secondary antibodies conjugated with Alexa Fluor- $594^{\circ}$ or Alexa Fluor- $488^{\circ}$ (1:100), respectively, slides were mounted in an aqueous medium (Mauwiol). The images of FDB skeletal muscle area were obtained by using Olympus BH-2 microscope (Tokyo, Japan) and Nikon digital camera DXM1200 (Melville, NY), at 4-20X magnification.

Analysis for the presence of neutrophil infiltrates followed the same procedure, with different samples incubated with primary antibodies against Ly6G (Zymed, 1:500), then incubated with secondary antibody conjugated with Alexa Fluor- $488^{\circ}$ (1:200). Samples from FDB skeletal muscle were investigated by confocal laser scanning microscopy (Leica TCS SP-5; Wetzlar, Germany). Control and treated samples were attached on slides and sealed using colorless nail polish. A Leica HCX PLAPO lambda 63x/1.4-0.6 oil immersion objective was fitted on the fluorescent microscope. Cell infiltrated fluorescence was observed at $488 \mathrm{~nm}$ laser wavelength excitation with emission spectrum from $639 \mathrm{~nm}$ to $701 \mathrm{~nm}$. The autofluorescence intensity of muscle cells of control and treated samples was calculated by 2 Section, 3 images each one, with an automatic standardized Region of Interest (ROI) where the intensity of each pixel was measured using the LAS-AF Lite program (Leica). The LAS-AF Lite program was also used for final processing of the confocal images.

\subsection{Analysis of pro-resolving pathways in the antihyperalgesic effect for HCE-CS or BML-111}

Paraffin embedded sections of the hindpaws of animals from different groups, harvested $49 \mathrm{~h}$ after paw reperfusion, were used for images assays for the expression of ALX/FPR2 or AnxA1, using double stainning immunofluorescence technique with methodology adapted from previous work (Patel et al., 2012). Samples of hind paws from animals belonging to different groups of treatment were embedded in paraffin, cut into microtome sections $(5 \mu \mathrm{m})$ and mounted on glass slides with subsequent rehydration. Antigen retrieval was performed in citrate buffer (pH 6.0) at $94{ }^{\circ} \mathrm{C}$ for 30 min then incubated, overnight, simultaneously with specific primary antibodies against AnxA1 (Zymed, 1:1000) or ALX/FPR2 (Santa Cruz, 1:4000) in a humid chamber. An antibody diluent was added to the negative control group in this stage (bovine serum albumin, 1\% BSA). The next day samples were simultaneosuly incubated with the secondary antibodies conjugated with Alexa Fluor $-350^{\circ}$ or Alexa Fluor $-488^{\circ}$, respectively, to develop the reaction the slides were mounted in an aqueous medium (Mauwiol). Samples were then investigated by confocal laser scanning microscopy, according to described technique (De Oliveira et al., 2016).

\subsection{Statistical analysis}

The Shapiro-Wilk test was used to evaluate the normality assumption of behavioral and biochemical data. All variables in the present study showed a normal distribution. Differences among experimental groups were determined by one or two-way ANOVA followed by Student-Newman-Keuls Multiple Comparison or Bonferroni post hoc Test, respectively, when appropriate. A value of $\mathrm{p}<0.05$ was considered to be statistically significant. All data are presented as mean + standard error of the mean (SEM).
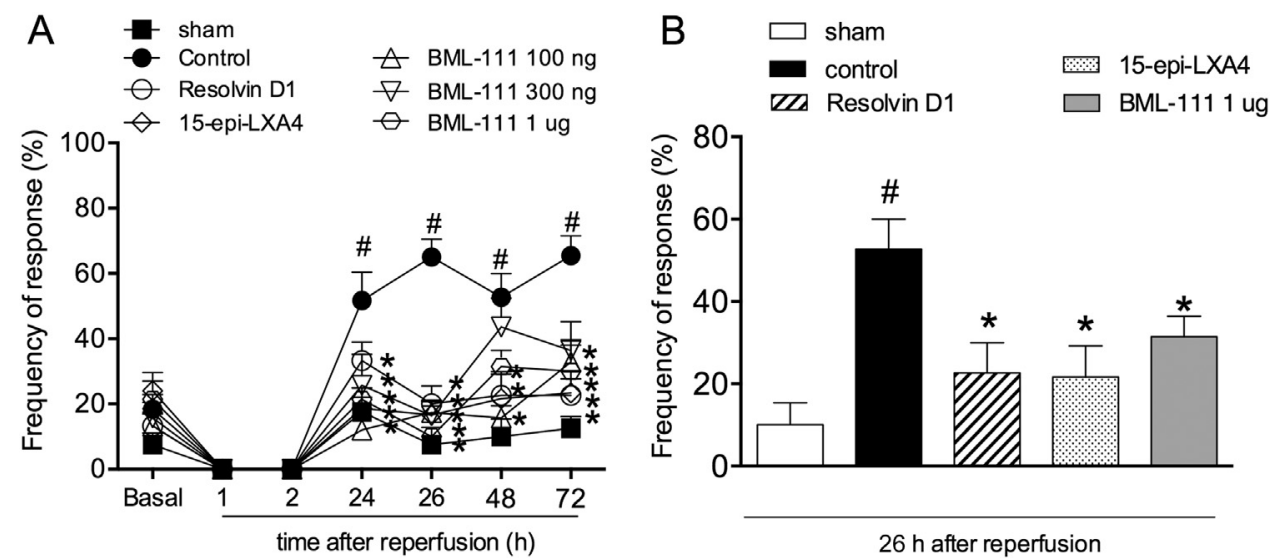

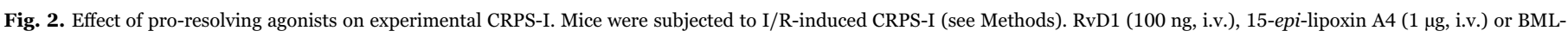

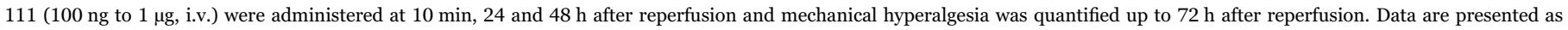
mean \pm S.E.M., $n=8$ (\# and * ${ }^{*}$ p $<0.05$ vs. sham or vehicle groups, respectively; Two-way ANOVA followed by Tukey's test (A) or One-way ANOVA followed by Bonferroni (B). 


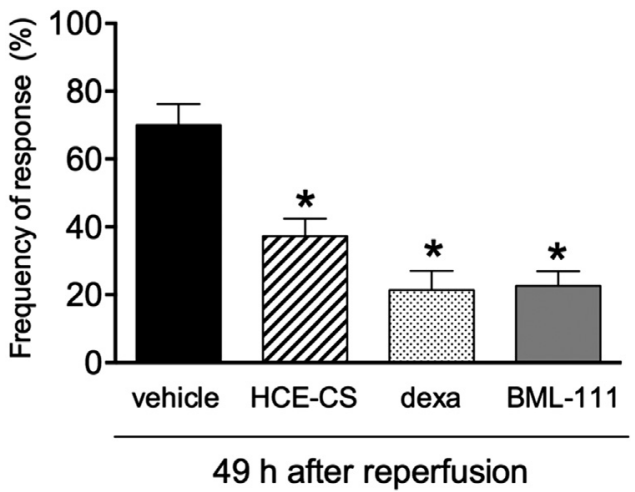

Fig. 3. Effect of HCE-CS in experimental CRPS-I: comparison to synthetic compounds. Mice were subjected to I/R-induced CRPS-I (see Methods). HCE-CS (30 mg/Kg p.o.), dexamethasone (dexa, $0.5 \mathrm{mg} / \mathrm{Kg}$, i.p) or BML-111 (BML, $1 \mu \mathrm{g}$, s.c) were administered at $10 \mathrm{~min}, 24$ and $48 \mathrm{~h}$ after reperfusion, with mechanical hyperalgesia measured $1 \mathrm{~h}$ after last administration. Data are mean \pm S.E.M., $n=8\left({ }^{*} \mathrm{p}<0.05\right.$ vs. vehicle controls; Oneway ANOVA followed by Tukey's test).

\section{Results}

\subsection{Influence of pro-resolving mediators in the CRPS-I model}

Treatment of the animals with different pro-resolving mediators at $10 \mathrm{~min}, 24$ and $48 \mathrm{~h}$ after I/R, reduced the mechanical hyperalgesia quantified in this model (Fig. 2). At $26 \mathrm{~h}$ after I/R, or $2 \mathrm{~h}$ after second treatment, RvD1 (21.7 $\pm 7.6 \%$ frequency of response), 15-epi-LXA4 $(22.7 \pm 7.3 \%)$ and BML-111 $(1 \mu \mathrm{g} / \mathrm{animal}: 31.4 \pm 5.0 \%)$ reduced frequency of response to von Frey filaments stimulus when compared to vehicle treated animals $(52.7 \pm 7.3 \%$ frequency of response).

\subsection{WRW4 prevents antihyperalgesic effect of HCE-CS or BML-111 during inflammatory phase of CRPS-I model}

We then tested the treatment with HCE-CS which evoked antihyperalgesic effects $(30 \mathrm{mg} / \mathrm{Kg}$, p.o., at $10 \mathrm{~min}, 24$ and $48 \mathrm{~h}$ after I/R) of similar magnitude to those observed with BML-111 ( $1 \mu \mathrm{g} / \mathrm{animal}$, s.c.) or dexamethasone $(0.5 \mathrm{mg} / \mathrm{Kg}$, p.o.; Fig. 3). Of interest, the antihyperalgesic effect of HCE-CS observed at $49 \mathrm{~h}$ was reversed by pretreatment of the animals with the antagonist WRW4 (Fig. 4).

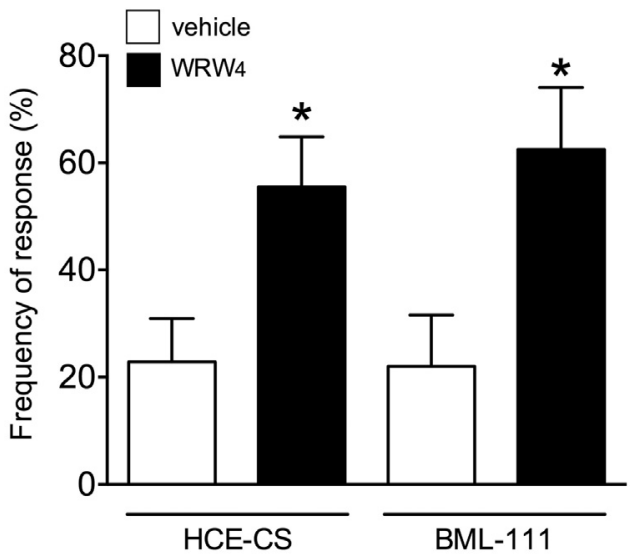

Fig. 4. Endogenous ALX/FPR2 mediates the control of experimental CRPS-I by HCECS. Mice were subjected to I/R-induced injury (see Methods). HCE-CS (30 mg/Kg p.o., open circles) or BML-111 (1 $\mu$ g, s.c., open triangles) were administered at $48 \mathrm{~h}$ postreperfusion, with or without the ALX/FPR2 antagonist (WRW4, $10 \mu \mathrm{g} / \mathrm{animal}$, s.c.) and mechanical allodynia was quantified $1 \mathrm{~h}$ thereafter. Data are presented as mean \pm S.E.M., $n=8\left({ }^{*} \mathrm{p}<0.05\right.$ vs. vehicle controls [closed circles]; Two-way ANOVA followed by Bonferroni test).

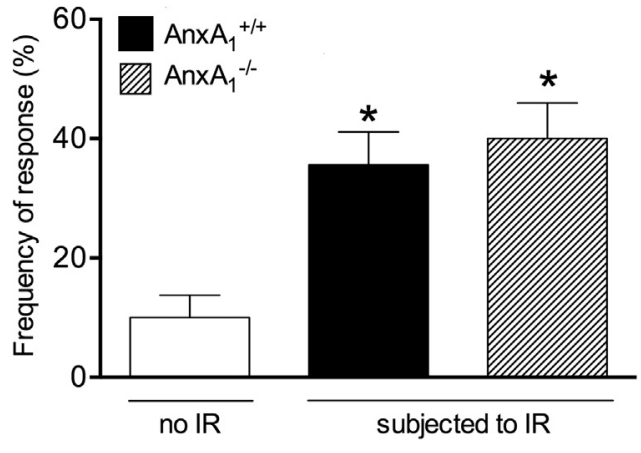

Fig. 5. Evaluation of functional impact of AnxA1 on mechanical hyperalgesia during inflammatory phase of CRPS-I model in mice. Wild type $\left(\mathrm{AnxA1}^{+/+}\right)$and knock out $\left(\mathrm{AnxA1}^{-/-}\right.$) mice were subjected to I/R-injury (see Methods) and mechanical hyperalgesia was assessed at $49 \mathrm{~h}$ after reperfusion. Data are presented as mean \pm S.E.M., $\mathrm{n}=8$ (Oneway ANOVA followed by Tukey's test).

\subsection{AnxA1 absence did not influence mechanical hyperalgesia during the inflammatory phase of CRPS-I}

Data presented in Fig. 5 indicate that at $49 \mathrm{~h}$ after I/R the frequency of response to von Frey monofilaments in $\mathrm{AnxA1}{ }^{+/+}$animals $(40.0 \pm$ $6.0 \%$ of response) was significantly higher than in sham group $(10.0 \pm$ $4.0 \%$ of response) with values not dissimilar in $\mathrm{AnxA1} 1^{-/-}$group $(36.0 \pm$ $6.0 \%$ of response).

\subsection{Histological analysis for the effects of HCE-CS on tissues alterations induced by $I / R$}

As shown in Fig. 6, a massive infiltration of inflammatory cells was observed at $49 \mathrm{~h}$ after reperfusion in FDB skeletal muscle adjacent to the metatarsal region. There was a significant increase in the number of cells in this tissue in animals from the experimental group (disease, $410.3 \pm 74.6$ cells) when compared to the control one (sham, $148.5 \pm$ 20.9 cells), and this effect was not influenced (Panel B) by treatment with the HCE-CS (470.5 \pm 67.1 cells) or selected pro-resolving mediator, BML- 111 (385.3 \pm 46.8 cells). Regarding the characterization of the cell infiltrate, Fig. 7 shows that the main cell type was the neutrophils, while lymphocyte and macrophage cells could not be readily detected in the tissue at this time point, given that no immunofluorescence-staining characteristic for CD3 or CD68 markers, respectively, was observed (data not shown).

\subsection{Involvement of LXA4-ALX/FPR2 pathway in the anti- hyperalgesic effect for $\mathrm{HCE}-\mathrm{CS}$}

At $49 \mathrm{~h}$ after reperfusion, skeletal muscle of the paw subjected to I/ $\mathrm{R}$ injury (disease) and neutrophils infiltrated to this tissue, did not express mediator AnxA1 (Fig. 8, Panel A). Besides of this, HCE-CS or BML-111 treatment increased the extent of ALX/FPR2 receptor expression in skeletal muscle and neutrophils in relation to disease group, as determined by immunofluorescence (Fig. 8, Panel B). In this last experiment, differences between sham and disease animals could not be compared once the architecture of the muscle cells was significantly affected by the disease.

Finally, no pannus formation was detected in the joints of treated animals as compared to the control group (sham). In a similar manner, I/R-induced injury (disease) did not cause cartilage erosion as monitored in a variety of joints in relation to the control group (sham). Both staining with Toluidine Blue (Fig. 9, panel A) or Fast Green + oSafranin (Fig. 9, panel B) were performed.

\section{Discussion}

The present study demonstrated that HCE from the leaves of 


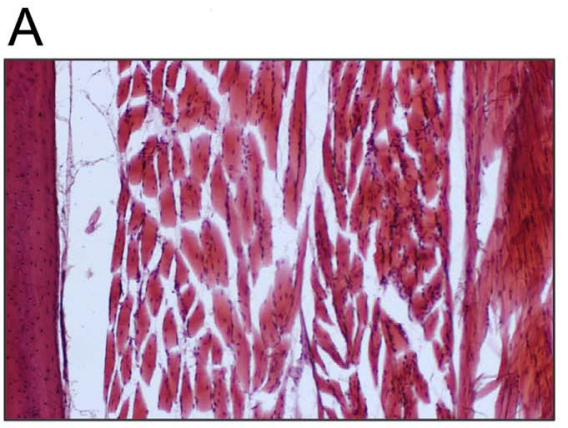

sham

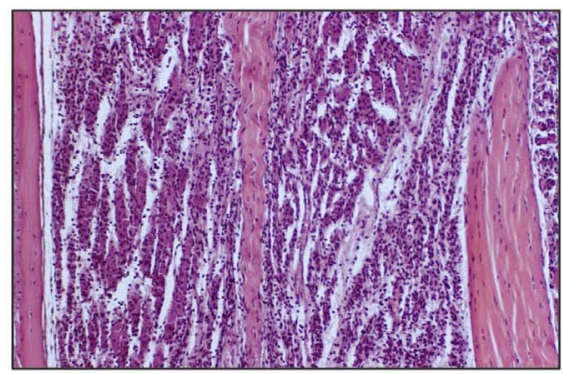

disease

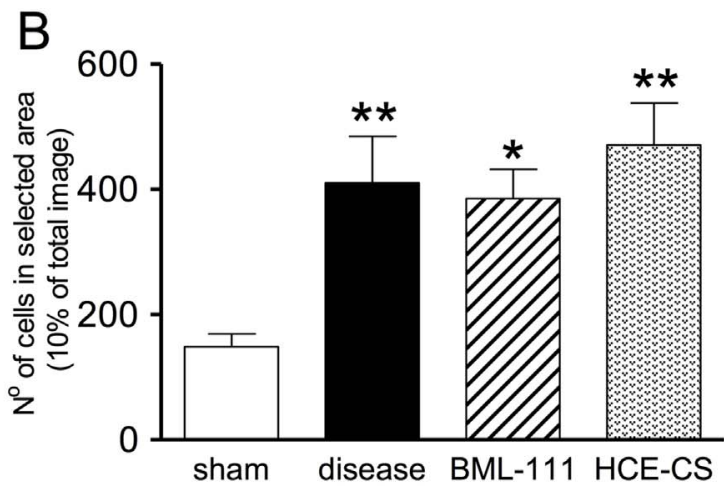

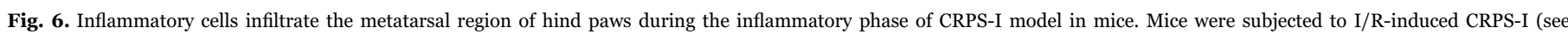

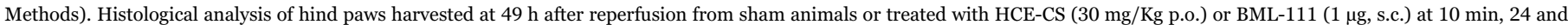
$48 \mathrm{~h}$ after reperfusion. In quantitative analysis data are presented as mean \pm S.E.M., $\mathrm{n}=8$ (One-way ANOVA followed by Tukey's test).
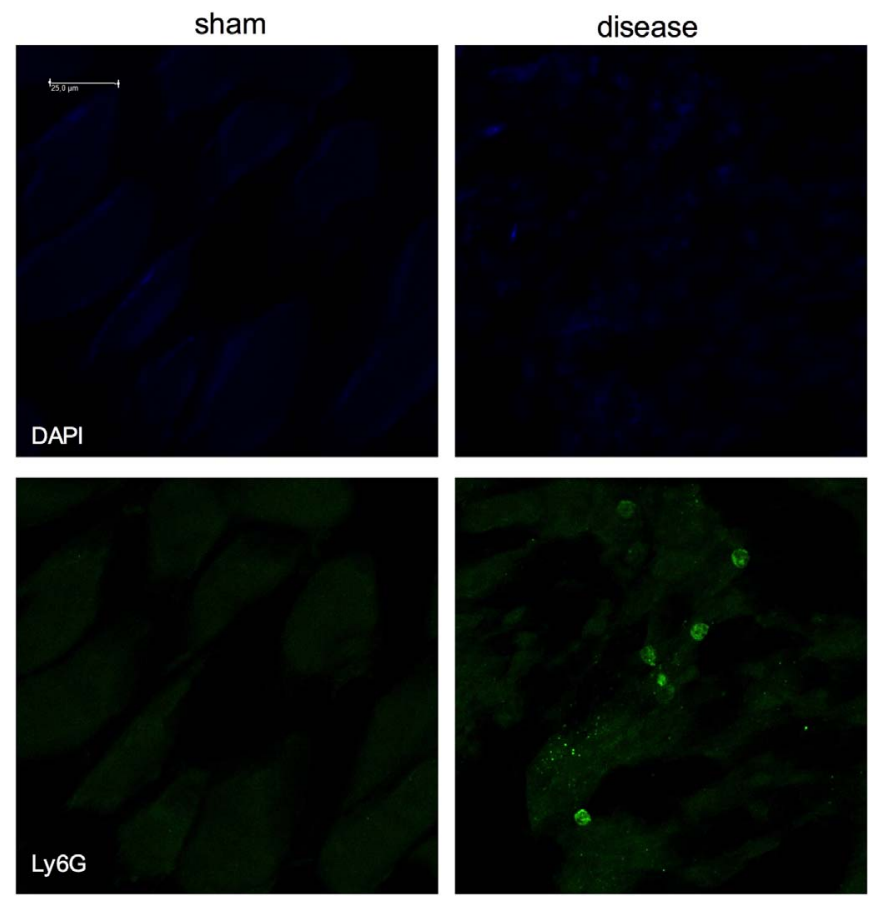

Fig. 7. Neutrophils are the main cell type inflitrating the metatarsal region of hind paws during the inflammatory phase of CRPS-I model in mice. Mice were subjected to I/Rinjury and immunfluorescence analysis (Ly6G for neutrophils; see Methods) was conducted in hind paws harvested at $49 \mathrm{~h}$ after reperfusion from animals belonging to the sham or disease groups.

Casearia sylvestris displayed powerful anti-hyperalgesic effect during the inflammatory phase of experimental CRPS-I. These data also indicate, likely for the first time, an involvement of the mechanisms of the resolution of inflammation in the properties of the plant extract leading to the suggestion that both classes of compounds (HCE-CS and pro-resolving mediators) can provide pharmacological tools for the treatment of this condition in humans.

CRPS-I is a debilitating disease, with a complex clinical presentation which importantly includes disturbances in sensorial perception leading to severe pain (Coderre and Bennett, 2010). Our findings that HCE-CS and pro-resolving mediators can reduce mechanical hyperalgesia is particularly important given that both classes of compounds (phytochemicals and pro-resolving lipid mediators) afforded efficacy similar to dexamethasone. While this last substance, from the glucocorticoid class, can be useful in the therapeutic management of CRPS-I, adverse effects are very well documented especially after chronic treatment. On these bases, new phamacological tools that control symptoms during the course of CRPS-I are of need.

With relation to possible mechanisms of action, it seems that this is the first study to evaluate contribution of resolution of inflammation pathways on antihyperalgesic effect exerted by an extract of plant. Chromatographic analysis of HCE-CS used in this study revealed the presence of several casearins including casearin-X, which was already implicated for its capability of coupling to GABA-A comples neuron receptors (De Araújo et al., 2017), what could influence pain phenomena. In the other hand, our results with the CRPS-I model demonstrate that a selective ALX/FPR2 antagonist (Shin et al., 2006), WRW4, prevented the antihyperalgesic action for HCE-CS or BML-111 implicating this receptor in modulatory mechanisms on nociception exerted by these treatments during the inflammatory phase of this experimental disease. These data unveil that HCE-CS and BMLL-111induced overexpression of this receptor occurs locally, both in skeletal muscle and in neutrophils at the site of I/R injured tissue. However, this receptor is also expressed centrally (Abdelmoaty et al., 2013) hence we cannot exclude a priori a role for central ALX/FPR2 in these pharmacoligical effects reported here. Within the periphery, inflitrated neutrophils but not lymphocytes or macrophages could be quantified though the treatments did not alter their values. One could propose 

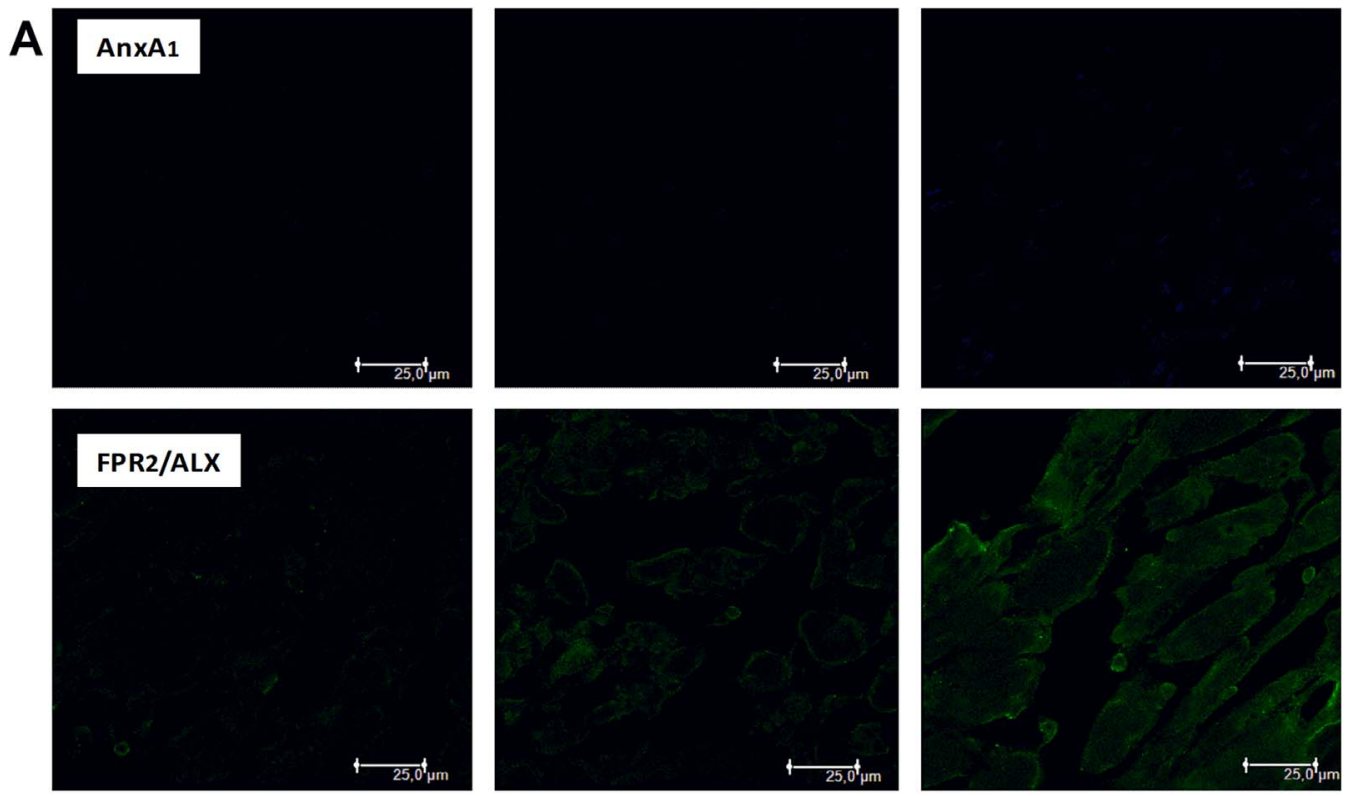

Disease

BML-111

HCE-CS

B

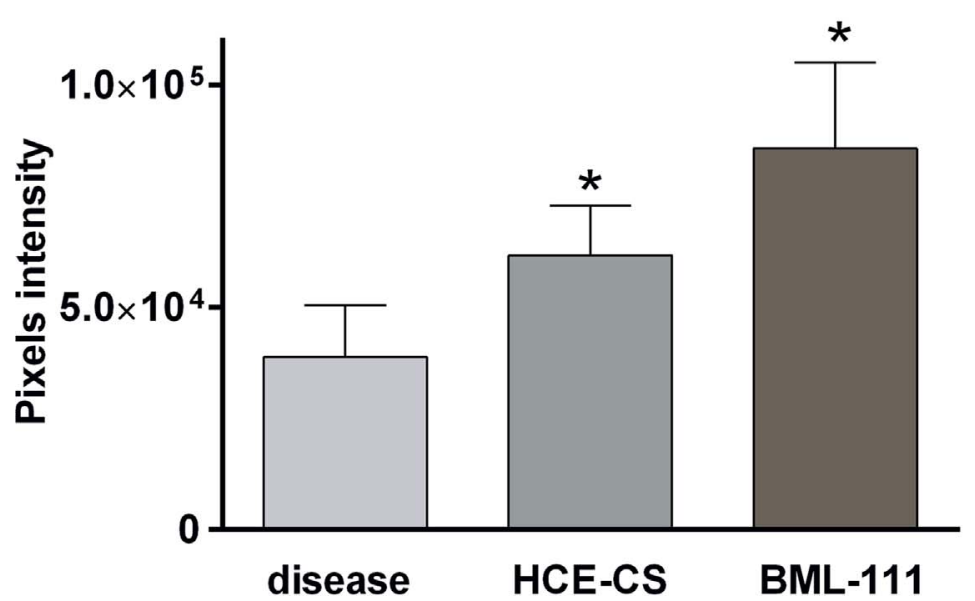

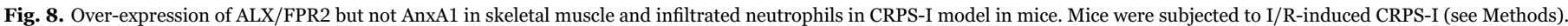

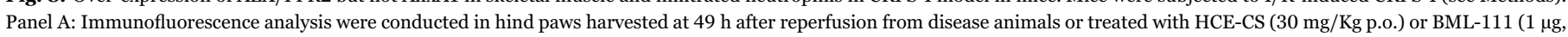
s.c.) at $10 \mathrm{~min}, 24$ and $48 \mathrm{~h}$ after reperfusion. Panel B: Quantitative data for ALX/FPR2 are presented as mean \pm S.E.M., $\mathrm{n}=8$ (One-way ANOVA followed by Tukey's test).

that the phenotype of the immune cells could have been changed by the anti-nociceptice treatments of which the higher expression of ALX/ FPR2 could be the marker. We note how this receptor is over-expressed following TNF application as well as upon contril by endogenous TNF in sepsis (Gobbetti et al., 2014). In human neutrophils, sex hormones promote an AnxA1+ALX/FPR2 phenotype (Nadkarni et al., 2011) which is associated with vascular protection (Nadkarni et al., 2014). It remains to be establish here what are the molecular determinants linking the plant extract and BML-111 to ALX/FPR2 over-expression but the functional data indicate a relevant engagement of this receptor in the effects described herein.

We propose that aside mast cells seems to contribute to CRPS-I (Huygen et al., 2004), is reasonable that neutrophil infiltration to the muscle might have implications to the nociceptive process observed in the present study, with appearing of mechanical hyperalgesia in I/Rinduced animal, since in humans decreased pressure pain threshold (muscle hyperalgesia) is one of the most proeminente sensory abnormalities observed (van Rooijen et al., 2013). Considering the present model of CPIP induced by I/R, these founds are also in agreement with the idea that targeting ALX/FPR2 receptors in both types of cells can be useful to treat symptoms of diseases in which pathophysiology relies importantly on vascular disturbances (Jones et al., 2016; Dufton and Perretti, 2010), specially those involving I/R-induced injuries (Gavins, 2010).

In view of the number of ligands that can interact with ALX/FPR2 receptor, it could be hard to identify the endogenous agonist responsible for the antihyperalgesic effects observed here, though AnxA1 and LXA4 are obvious candidates. However, based on our behavioral experiments as well as on recent published studies, we can indicate LXA4 as the most likely mediator involved in these actions. Firstly, BML-111 is a synthetic analog for LXA4 and it produced biological effects through interaction with the ALX/FPR2 receptor as reported in several systems (Sordi et al., 2013; Wu et al., 2016). Secondly, LXA4 levels are increased in mice in a model of $I / R$, specially after reperfusion stage, in which large amounts of neutrophil/platelet aggregates are formed (Brancaleone et al., 2013). In vitro, LXA4 exerts powerful tissue protective effects on rat cardiomyocites after I/R through up-regulation of heme oxygenase-1 (Chen et al., 2013), 

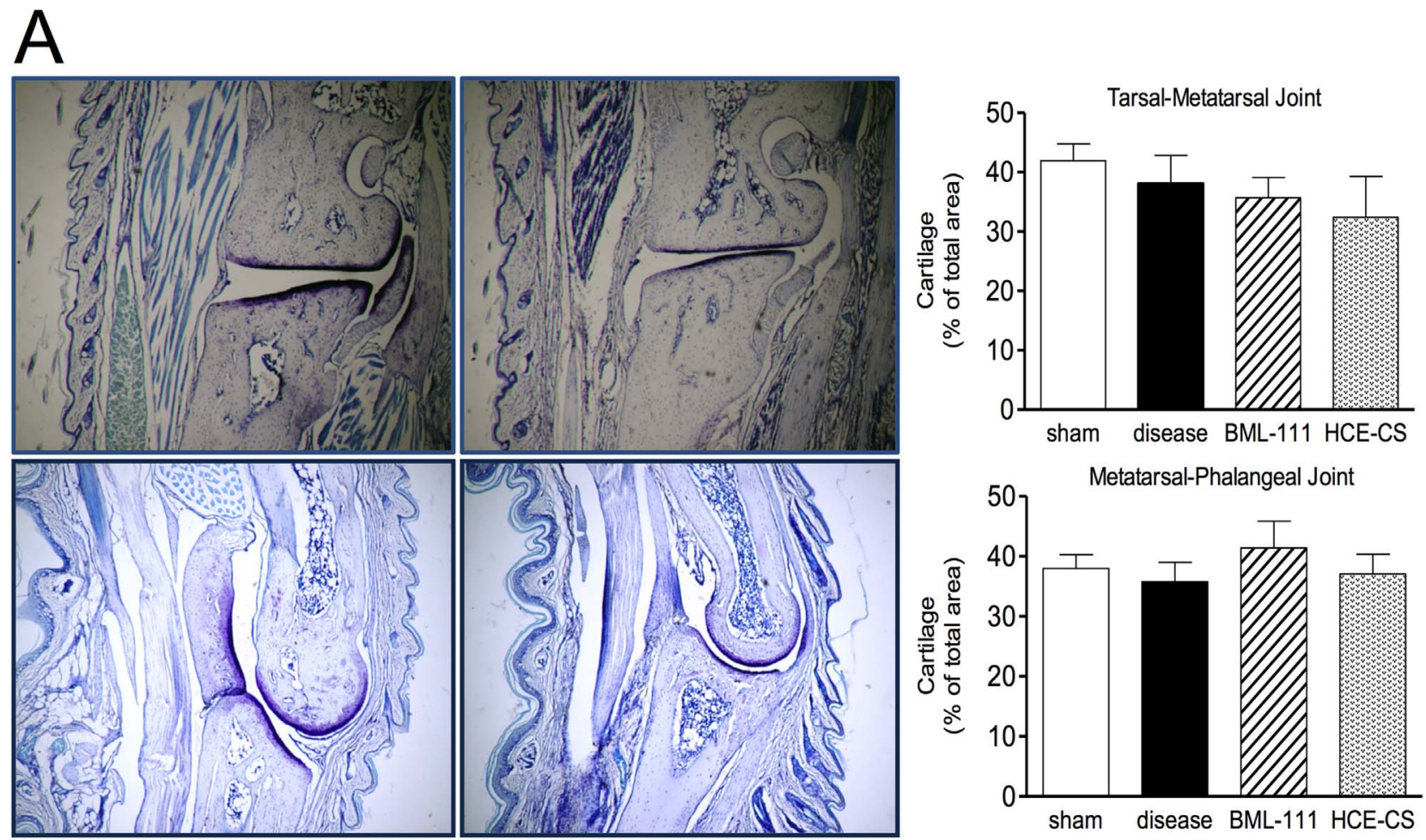

\section{$\mathrm{B}$}
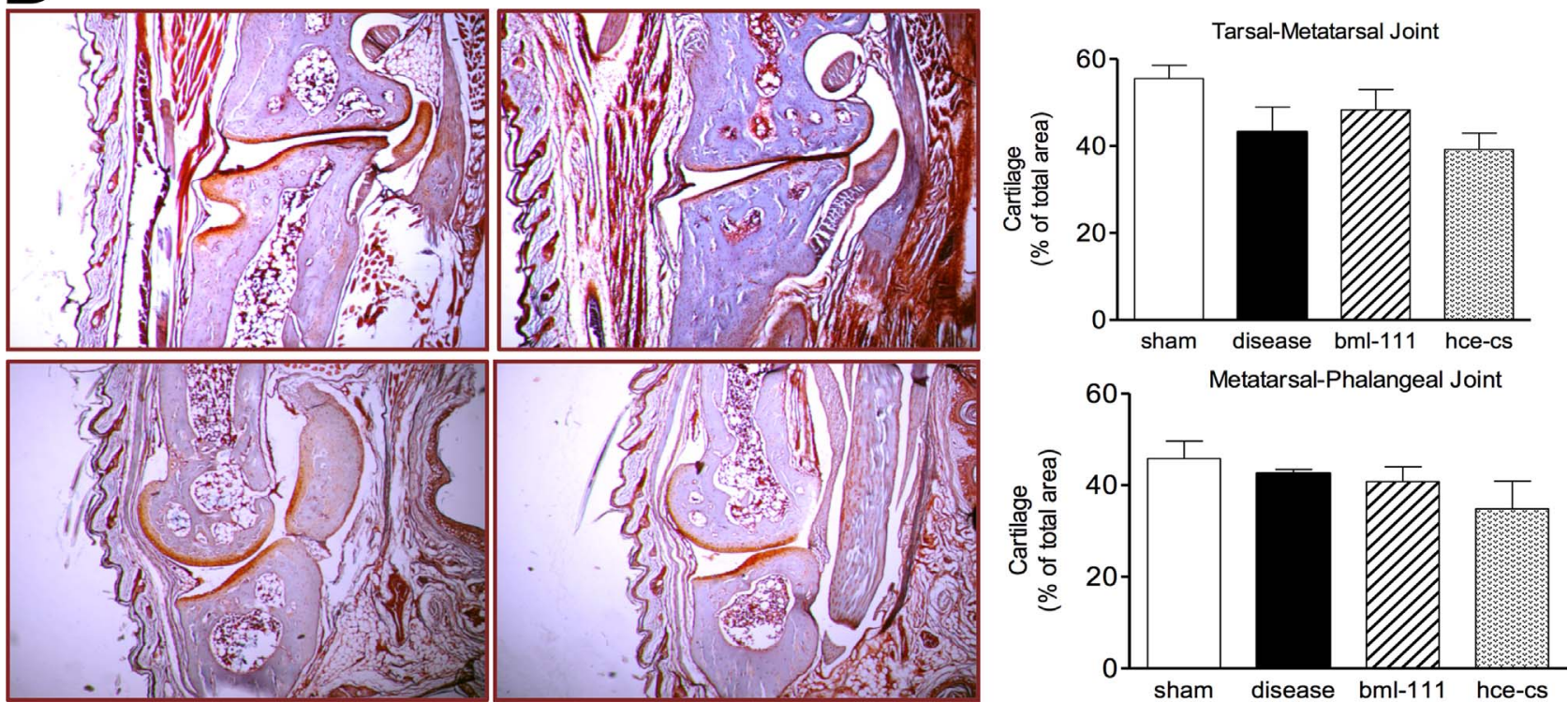

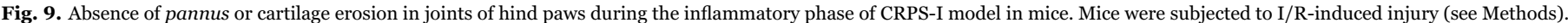

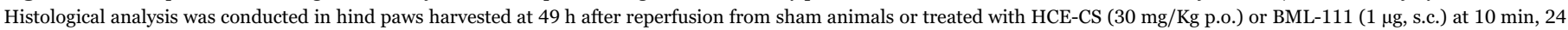
and $48 \mathrm{~h}$ after reperfusion. In quantitative analysis data are presented as mean \pm S.E.M., $\mathrm{n}=8$ (One-way ANOVA followed by Tukey's test).

downregulation of GRP-78 and caspase-12, as well as inhibition of cell apoptosis; while in vivo, the mediator was also beneficial to vascular smooth muscle cells in a mouse model of carotid artery ligation (Zhao et al., 2014). At variance from LXA4, our data exclude presence and functional involvement of AnxA1 since this protein was not particularly abundant at the site of injury and its absence in the knock out mice failed to influence mechanical hyperalgesia. This last result is in agreement with recently published, in which muscles in AnxA1deficient mice were not affected in size or in repair of myofibers following application of different types of injuries (Leikina et al., 2015).

Altogether these data allow us to speculate that during the inflammatory phase of a mouse CRPS-I model, ALX/FPR2 expressed in neutrophils and skeletal muscle is targeted by HCE-CS, directly or indirectly through endogenous LXA4 release (an effect mimicked by the pharmacological delivery of BML-111). Engagement of ALX/FPR2 would in turn reduce mechanical hyperalgesia promoted by derangement in this tissue. Antihyperalgesic effect for LXA4 and its derivatives is very well documented in different animal models (Petri et al., 2015; Wang et al., 2014; Abdelmoaty et al., 2013). On other hand HCE-CS has already presented antinociceptive action (De Mattos et al., , 2007) and it can also evoke antiinflamatory and antioxidant properties (Albano et al., 2013). 
Finally, regarding our present findings from histological analysis, besides other models of CRPS-I induced by nerve ligation (Li et al., 2013) or auto-immunity (Goebel and Blaes, 2013) have also been described, in the present study we used a model of CRPS-I caused by I/ $\mathrm{R}$ wich faithfully reproduces human symptoms (Laferrière et al., 2008). Currently, morphological alterations observed during CRPS-I is not related to nerve injury or bone alterations, specially during initial phases of the disease; however, changes in skin, specially in microcirculation, and muscle tissues have been found (Coderre and Bennett, 2010; Millecamps et al., 2010). In muscles, patients who have suffered amputation of the affected limb, presented major disturbances such as fatty degeneration, atrophy of fibers and nuclear agglomeration, not related to the duration of the syndrome, while extensor and flexor muscles of the forearm from other patients were affected as evaluated by ultrassonography (Goebel and Blaes, 2013; Vas et al., 2013; Huang et al., 2011; Schürmann et al., 2007). This results are in accordance with our histological data demonstrating no alterations in cartilage nor pannus formation at the joints of animals from disease group while, in the contrary, skeletal muscle was massively surrounded by infiltration of inflammatory cells which, as expected, were not present in sham group.

\section{Conclusion}

We presented evidence that demonstrate the involvement of a pathway of resolution of inflammation centred on LXA4 and the receptor ALX/FPR2 in the antihyperalgesic effect for HCE-CS and BML-111 during the inflammatory phase of CPIP model. These results also suggest a potential role for endogenous pro-resolving mediators in the pharmacological properties of Casearia sylvestris extract, a conclusion that may have dual implications with respect to innovative therapies for this debilitating conditions: i) use the extract as a novel treatment for CRPS-I in humans and ii) develop ALX/FPR2 agonists, likely modeled on LXA4, as novel scaffold for therapeutic development.

\section{Authors and contributions}

- Anna P. Piovezan: author make substantial contributions to conception and design, and/or acquisition of data, and/or analysis and interpretation of data, participate in drafting the article or revising it critically for important intellectual contente and give final approval of the version to be submitted and any revised version.

- Ana P. Batisti: author make substantial contributions to acquisition of data, participate in drafting the article and give final approval of the version to be submitted.

- Maria L.A.C.S. Benevides: author make substantial contributions to acquisition of data, participate in drafting the article and give final approval of the version to be submitted.

- Bruna L. Turnes: author make substantial contributions to acquisition of data, participate in drafting the article and give final approval of the version to be submitted.

- Daniel F. Martins: author make substantial contributions to conception and design and analysis and interpretation of data, participate in drafting the article or revising it critically for important intellectual contente and give final approval of the version to be submitted and any revised version.

- Luiz Kanis: author make substantial contributions to design, participate in drafting the article or revising it critically for important intellectual contente and give final approval of the version to be submitted.

- Elisa C.W. Duarte: author make substantial contributions to design, participate in drafting the article or revising it critically for important intellectual contente and give final approval of the version to be submitted.

- Alberto J. Cavalheiro: author make substantial contributions to design, participate in drafting the article or revising it critically for important intellectual contente and give final approval of the version to be submitted.

- Paula C. P. Bueno: author make substantial contributions to design, participate in drafting the article or revising it critically for important intellectual contente and give final approval of the version to be submitted.

- Michael P. Seed: author make substantial contributions to design, participate in drafting the article or revising it critically for important intellectual contente and give final approval of the version to be submitted.

- Lucy V. Norling: author make substantial contributions to design, participate in drafting the article or revising it critically for important intellectual contente and give final approval of the version to be submitted.

- Dianne Cooper: author make substantial contributions to design, participate in drafting the article or revising it critically for important intellectual contente and give final approval of the version to be submitted.

- Sarah Headland: author make substantial contributions to design, participate in drafting the article or revising it critically for important intellectual contente and give final approval of the version to be submitted.

- Patrícia R.P.S. Souza: author make substantial contributions to design, participate in drafting the article or revising it critically for important intellectual contente and give final approval of the version to be submitted.

- Mauro Perretti: author make substantial contributions to conception and design, and/or analysis and interpretation of data, participate in drafting the article or revising it critically for important intellectual contente and give final approval of the version to be submitted and any revised version.

\section{Conflict of interest}

The authors declare that they have no conflicts of interest.

\section{Acknowledgements}

This work was supported by CNPq - Conselho Nacional de Desenvolvimento Científico e Tecnológico -, FAPESC - Fundação de Amparo à Pesquisa e Inovação do Estado de Santa Catarina-, UNISUL (Brazil) and European Union's Seventh Framework Programme (FP7/ 2007-2013) CoFund (Marie Curie Actions; WHRI Academy) under REA grant agreement $n^{\circ} 608765$ ". Contents reflect only the author's views and not the views of the European Commission. Maria L.A.C.S. Benevides received PIBIC-CNPq/UNISUL scholarship.

\section{References}

Abdelmoaty, S., Wigerblad, G., Bas, D.B., Codeluppi, S., Fernandez-Zafra, T., El-Awady, el-S., Moustafa, Y., Abdelhamid, Ael-D., Brodin, E., Svensson, C.I., 2013. Spinal actions of lipoxin A4 and 17(R)-resolvin D1 attenuate inflammation-induced mechanical hypersensitivity and spinal TNF release. PLoS One 8, e75543.

Albano, M.N., da Silveira, M.R., Danielski, L.G., Florentino, D., Petronilho, F., Piovezan, A.P., 2013. Anti-inflammatory and antioxidant properties of hydroalcoholic crude extract from Casearia sylvestris Sw. (Salicaceae). J. Ethnopharmacol. 147, 612-617.

Borges, M.H., Soares, A.M., Rodrigues, V.M., Oliveira, F., Fransheschi, A.M., Rucavado, A., Giglio, J.R., Homsi-Brandeburgo, M.I., 2001. Neutralization of proteases from Bothrops snake venoms by the aqueous extract from Casearia sylvestris (Flacourtiaceae). Toxicon 39, 1863-1869.

Borges, M.H., Soares, A.M., Rodrigues, V.M., Andrião-Escarso, S.H., Diniz, H., Hamaguchi, A., Quintero, A., Lizano, S., Gutiérrez, J.M., Giglio, J.R., HomsiBrandeburgo, M.I., 2000. Effects of aqueous extract of Casearia sylvestris (Flacourtiaceae) on actions of snake and bee venoms and on activity of phospholipases A2. Comp. Biochem Physiol. B Biochem Mol. Biol. 127, 21-30.

Bou, D.D., Lago, J.H., Figueiredo, C.R., Matsuo, A.L., Guadagnin, R.C., Soares, M.G., Sartorelli, P., 2013. Chemical composition and cytotoxicity evaluation of essential oil from leaves of Casearia sylvestris, its main compound a-zingiberene and derivatives. Molecules 18, 9477-9487.

Brancaleone, V., Gobbetti, T., Cenac, N., Le Faouder, P., Colom, B., Flower, R.J., Vergnolle, N., Nourshargh, S., Perretti, M., 2013. A vasculo-protective circuit 
centered on lipoxin A4 and aspirin-triggered 15-epi-lipoxin A4 operative in murine microcirculation. Blood 122, 608-617.

Bueno, P.C., Pereira, F.M., Torres, R.B., Cavalheiro, A.J., 2015. Development of a comprehensive method for analyzing clerodane-type diterpenes and phenolic compounds from Casearia sylvestris Swartz (Salicaceae) based on ultra high performance liquid chromatography combined with chemometric tools. J. Sep. Sci. 38, 1649-1656.

Cash, J.L., Norling, L.V., Perretti, M., 2014. Resolution of inflammation: targeting GPCRs that interact with lipids and peptides. Drug Discov. Today 19, 1186-1192.

Chen, X.Q., Wu, S.H., Zhou, Y., Tang, Y.R., 2013. Lipoxin A4-induced heme oxygenase-1 protects cardiomyocytes against hypoxia/reoxygenation injury via p38 MAPK activation and Nrf2/ARE complex. PLoS One 8, e67120.

Coderre, T.J., Bennett, G.J., 2010. A hypothesis for the cause of complex regional pain syndrome-type I (reflex sympathetic dystrophy): pain due to deep-tissue microvascular pathology. Pain. Med 11, 1224-1238.

Coderre, T.J., Xanthos, D.N., Francis, L., Bennett, G.J., 2004. Chronic post-ischemia pain (CPIP): a novel animal model of complex regional pain syndrome-type I (CRPS-I; reflex sympathetic dystrophy) produced by prolonged hindpaw ischemia and reperfusion in the rat. Pain 112, 94-105.

De Araújo, É.J., de Almeida, A.A., Silva, O.A., da Costa, I.H., Rezende-Júnior, L.M., Lima, F.D., Cavalheiro, A.J., Pessoa, C., de Moraes, M.O., Ferreira, P.M., 2017. Behavioral effects induced by antitumor cleronade diterpenes from Casearia sylvestris and in silico interactions with neuron receptors. J. Ethnopharmacol. 198, 460-467.

De Mattos, E.S., Frederico, M.J., Colle, T.D., de Pieri, D.V., Peters, R.R., Piovezan, A.P. Evaluation of antinociceptive activity of Casearia sylvestris and possible mechanism of action. J Ethnopharmacol 112, 1-6.

De Oliveira, E.M., Schmidt, E.C., Pereira, D.T., Bouzona, Z.L., Ouriques, L.C., 2016. Effects of UV-B radiation on germlings of the red macroalga Nemalion helminthoides (Rhodophyta). JMAU 4, 85-94.

Dos Santos, A.G., Ferreira, P.M., Vieira Júnior, G.M., Perez, C.C., Gomes Tininis, A., Silva, G.H., Bolzani, V., da, S., Costa-Lotufo, L.V., Pessoa, C., do, O., Cavalheiro, A.J., 2010. Casearin X, its degradation product and other clerodane diterpenes from leaves of Casearia sylvestris: evaluation of cytotoxicity against normal and tumor human cells. Chem. Biodivers. 7, 205-215.

Dufton, N., Perretti, M., 2010. Therapeutic anti-inflammatory potential of formyl-peptide receptor agonists. Pharmacol. Ther. 127, 175-188.

Ferreira, P.M., Costa-Lotufo, L.V., Moraes, M.O., Barros, F.W., Martins, A.M., Cavalheiro, A.J., Bolzani, V.S., Santos, A.G., Pessoa, C., 2011. Folk uses and pharmacological properties of Casearia sylvestris: a medicinal review. Acad. Bras. Cienc. 83, 1373-1384.

Gavins, F.N., 2010. Are formyl peptide receptors novel targets for therapeutic intervention in ischaemia-reperfusion injury? Trends Pharmacol. Sci. 31, 266-276.

Gobbetti, T., Coldewey, S.M., Chen, J., McArthur, S., le Faouder, P., Cenac, N., Flower, R.J., Thiemermann, C., Perretti, M., 2014. Nonredundant protective properties of FPR2/ALX in polymicrobial murine sepsis. Proc. Natl. Acad. Sci. USA 111, $18685-18690$.

Goebel, A., Blaes, F., 2013. Complex regional pain syndrome, prototype of a novel kind of autoimmune disease. Autoimmun. Rev. 12, 682-686.

Headland, S.E., Jones, H.R., Norling, L.V., Kim, A., Souza, P.R., Corsiero, E., Gil, C.D., Nerviani, A., Dell'Accio, F., Pitzalis, C., Oliani, S.M., Jan, L.Y., Perretti, M., 2015. Neutrophil-derived microvesicles enter cartilage and protect the joint in inflammatory arthritis. Sci. Transl. Med 7, 315ra190.

Hu, S., Mao-Ying, Q.L., Wang, J., Wang, Z.F., Mi, W.L., Wang, X.W., Jiang, J.W., Huang, Y.L., Wu, G.C., Wang, Y.Q., 2012. Lipoxins and aspirin-triggered lipoxin alleviate bone cancer pain in association with suppressing expression of spinal proinflammatory cytokines. J. Neuroinflamm. 9, 278.

Huang, L., Wang, C.F., Serhan, C.N., Strichartz, G., 2011. Enduring prevention and transient reduction of postoperative pain by intrathecal resolvin D1. Pain 152, $557-565$.

Huygen, F.J., Ramdhani, N., van Toorenenbergen, A., Klein, J., Zijlstra, F.J., 2004. Mast cells are involved in inflammatory reactions during Complex Regional Pain Syndrome type 1. Immunol. Lett. 91, 147-154.

Jones, H.R., Robb, C.T., Perretti, M., Rossi, A.G., 2016. The role of neutrophils in inflammation resolution. Semin Immunol. 28, 137-145.

Laferrière, A., Millecamps, M., Xanthos, D.N., Xiao, W.H., Siau, C., de Mos, M., Sachot, C., Ragavendran, J.V., Huygen, F.J., Bennett, G.J., Coderre, T.J., 2008. Cutaneous tactile allodynia associated with microvascular dysfunction in muscle. Mol. Pain. 4, 49.

Leikina, E., Defour, A., Melikov, K., Van der Meulen, J.H., Nagaraju, K., Bhuvanendran, S., Gebert, C., Pfeifer, K., Chernomordik, L.V., Jaiswal, J.K., 2015. Annexin A1 Deficiency does not affect myofiber repair but delays regeneration of injured muscles. Sci. Rep. 5, 18246.

Leinster, D.A., Kulbe, H., Everitt, G., Thompson, R., Perretti, M., Gavins, F.N., Cooper, D., Gould, D., Ennis, D.P., Lockley, M., McNeish, I.A., Nourshargh, S., Balkwill, F.R., 2012. The peritoneal tumour microenvironment of high-grade serous ovarian cancer.
J. Pathol, 227, 136-145.

Li, Q., Tian, Y., Wang, Z.F., Liu, S.B., Mi, W.L., Ma, H.J., Wu, G.C., Wang, J., Yu, J., Wang, Y.Q., 2013. Involvement of the spinal NALP1 inflammasome in neuropathic pain and aspirin-triggered-15-epi-lipoxin A4 induced analgesia. Neuroscience 254, 230-240.

Liu, Z.H., Miao, G.S., Wang, J.N., Yang, C.X., Fu, Z.J., Sun, T., 2016. Resolvin D1 inhibits mechanical hypersensitivity in sciatica by modulating the expression of nuclear factor- $\mathrm{kB}$, phospho-extracellular signal-regulated kinase, and pro- and antiinflammatory cytokines in the spinal cord and dorsal root ganglion. Anesthesiology 124, 934-944.

Martins, D.F., Mazzardo-Martins, L., Soldi, F., Stramosk, J., Piovezan, A.P., Santos, A.R., 2013. High-intensity swimming exercise reduces neuropathic pain in an animal model of complex regional pain syndrome type I: evidence for a role of the adenosinergic system. Neuroscience 234, 69-76.

Meesakul, P., Ritthiwigrom, T., Cheenpracha, S., Sripisut, T., Maneerat, W., Machan, T. Laphookhieo, S., 2016. A new cytotoxic clerodane diterpene from Casearia graveolens Twigs. Nat. Prod. Commun. 11, 13-15.

Millecamps, M., Laferrière, A., Ragavendran, J.V., Stone, L.S., Coderre, T.J., 2010. Role of peripheral endothelin receptors in an animal model of complex regional pain syndrome type 1 (CRPS-I). Pain 151, 174-183.

Nadkarni, S., Cooper, D., Brancaleone, V., Bena, S., Perretti, M., 2011. Activation of the annexin A1 pathway underlies the protective effects exerted by estrogen in polymorphonuclear leukocytes. Arterioscler. Thromb. Vasc. Biol. 31, 2749-2759.

Nadkarni, S., Dalli, J., Hollywood, J., Mason, J.C., Dasgupta, B., Perretti, M., 2014. Investigational analysis reveals a potential role for neutrophils in giant-cell arteritis disease progression. Circ. Res 114, 242-248.

Norling, L.V., Headland, S.E., Dalli, J., Arnardottir, H.H., Haworth, O., Jones, H.R., Irimia, D., Serhan, C.N., Perretti, M., 2016. Proresolving and cartilage-protective actions of resolvin D1 in inflammatory arthritis. JCI Insight 1, e85922.

Patel, H.B., Kornerup, K.N., Sampaio, A.L., D'Acquisto, F., Seed, M.P., Girol, A.P., Gray, M., Pitzalis, C., Oliani, S.M., Perretti, M., 2012. The impact of endogenous annexin A1 on glucocorticoid control of inflammatory arthritis. Ann. Rheum. Dis. 71 $1872-1880$.

Pei, L., Zhang, J., Zhao, F., Su, T., Wei, H., Tian, J., Li, M., Shi, J., 2011. Annexin 1 exerts anti-nociceptive effects after peripheral inflammatory pain through formyl-peptidereceptor-like 1 in rat dorsal root ganglion. Br. J. Anaesth. 107, 948-958.

Perretti, M., 2015. The resolution of inflammation: new mechanisms in patho-physiology open opportunities for pharmacology. Semin Immunol. 27, 145-148.

Petri, M.H., Laguna-Fernandez, A., Tseng, C.N., Hedin, U., Perretti, M., Bäck, M., 2015. Aspirin-triggered 15-epi-lipoxin A4 signals through FPR2/ALX in vascular smooth muscle cells and protects against intimal hyperplasia after carotid ligation. Int J. Cardiol. 179, 370-372.

Pieretti, S., Di Giannuario, A., De Felice, M., Perretti, M., Cirino, G., 2001. Stimulusdependent specificity for annexin 1 inhibition of the inflammatory nociceptive response: the involvement of the receptor for formylated peptides. Pain 109, 52-63.

Schürmann, M., Zaspel, J., Löhr, P., Wizgall, I., Tutic, M., Manthey, N., Steinborn, M., Gradl, G., 2007. Imaging in early posttraumatic complex regional pain syndrome: a comparison of diagnostic methods. Clin. J. Pain. 23, 449-457.

Serhan, C.N., Chiang, N., 2008. Endogenous pro-resolving and anti-inflammatory lipid mediators: a new pharmacologic genus. Br. J. Pharmacol. 153, S200-15.

Shin, E.H., Lee, H.Y., Kim, S.D., Jo, S.H., Kim, M.K., Park, K.S., Lee, H., Bae, Y.S., 2006. Trp-Arg-Trp-Trp-Trp-Trp antagonizes formyl peptide receptor like 2-mediated signaling. Biochem Biophys. Res Commun. 341, 1317-1322.

Sordi, R., Menezes-de-Lima, O., Jr, Horewicz, V., Scheschowitsch, K., Santos, L.F., Assreuy, J., 2013. Dual role of lipoxin A4 in pneumosepsis pathogenesis. Int Immunopharmacol. 17, 283-292.

Sun, T., Yu, E., Yu, L., Luo, J., Li, H., Fu, Z., 2012. LipoxinA(4) induced antinociception and decreased expression of NF- $\mathrm{kB}$ and pro-inflammatory cytokines after chronic dorsal root ganglia compression in rats. Eur. J. Pain. 16, 18-27.

van Rooijen, D.E., Marinus, J., Schouten, A.C., Noldus, L.P., van Hilten, J.J., 2013 Muscle hyperalgesia correlates with motor function in complex regional pain syndrome type 1. J. Pain. 14, 446-454.

Vas, L.C., Pai, R., Radhakrishnan, M., 2013. Ultrasound appearance of forearm muscles in 18 patients with complex regional pain syndrome 1 of the upper extremity. Pain. Pract. 13, 76-88.

Wang, Z.F., Li, Q., Liu, S.B., Mi, W.L., Hu, S., Zhao, J., Tian, Y., Mao-Ying, Q.L., Jiang, J.W., Ma, H.J., Wang, Y.Q., Wu, G.C., 2014. Aspirin-triggered Lipoxin A4 attenuates mechanical allodynia in association with inhibiting spinal JAK2/STAT3 signaling in neuropathic pain in rats. Neuroscience 273, 65-78.

Wu, S.H., Chen, X.Q., Lü, J., Wang, M.J., 2016. BML-111 attenuates renal ischemia/ reperfusion injury via peroxisome proliferator-activated receptor-a-regulated heme oxygenase-1. Inflammation 39, 611-624.

Zhao, Q., Hu, X., Shao, L., Wu, G., Du, J., Xia, J., 2014. LipoxinA4 attenuates myocardial ischemia reperfusion injury via a mechanism related to downregulation of GRP-78 and caspase-12 in rats. Heart Vessels 29, 667-678. 